\title{
ПРОБЛЕМЫ ПРОГНОЗИРОВАНИЯ РЫНКА ИМПОРТОЗАМЕЩАЮЩЕЙ ПРОДУКЦИИ
}

\section{PROBLEMS OF FORECASTING THE MARKET OF IMPORT-SUBSTITUTING PRODUCTS}

\section{A. Ovchinnikov}

Summary. The issues of forecasting the development of the market of import-substituting products are characterized by increased relevance. This is due not only to the state's import substitution policy, but also to the need to build objective guidelines regarding the prospects for the development of relevant markets for business entities. Forecasting the market of import-substituting products faces a number of objective and subjective problems that require separate analysis and finding ways to solve them. These are problems related to the uncertainty of the prospects for implementing the state policy of import substitution, the boundaries of the market for import substitution products, the presence of various segments of this market, and other problems. The article reveals the main problems of forecasting the market of importsubstituting products and identifies ways to solve them.

Keywords: forecasting, the market of import-substituting products, features, problems.

\author{
Овчинников Алексей Павлович \\ К.э.н., доцент, Российский университет \\ транспорта (МИИТ) \\ alexovchinnikov@mail.ru
}

Аннотачия. Вопросы прогнозирования развития рынка импортозамещающей продукции характеризуются повышенной актуальностью. Это связано не только с проводимой государством политикой импортозамещения, но и необходимостью построения объективных ориентиров в части перспектив развития соответствующих рынков для субъектов предпринимательской деятельности. Прогнозирование рынка импортозамещающей продукции сталкивается с рядом объективных и субъективных проблем, требующих отдельного анализа и поиска путей их решения. Это проблемы, связанные с неопределенностью перспектив осуществления государственной политики импортозамещения, границами рынка продукции импортозамещения, наличием различных сегментов данного рынка и другие проблемы. В статье раскрываются основные проблемы прогнозирования рынка импортозамещающей продукции и определяются пути их решения.

Ключевые слова: прогнозирование, рынок импортозамещающей продукции, особенности, проблемы.

вопросам осуществления политики импортозамещения стратегический документ. Все вопросы стратегического планирования реализации политики импортозамещения «разбросаны» по различным актам. Это существенно затрудняет возможность построения адекватных прогнозов развития рынков импортозамещения на средне- и долгосрочный период.

Проводимая государством политика импортозамещения находится в существенной зависимости от внешнеполитической и внешнеэкономической ситуации - по сути, говорить о стабильности данного направления государственной экономической политики в современных условиях не приходится. Любое изменение во внешней среде, связанное с улучшением отношений России со странами Запада с большой долей вероятности повлечет отмену или исключение отдельных элементов в структуре политики импортозамещения. В таком случае потребуется пересмотр сформированных прогнозов.

Среди документов долгосрочного планирования Российской Федерации, в которых отражены отдель- 
ные элементы политики импортозамещения, можно выделить следующие:

- Стратегия национальной безопасности Российской Федерации;

- Стратегия экономической безопасности Российской Федерации на период до 2030 года;

- О национальных целях и стратегических задачах развития Российской Федерации на период до 2024 года (Указ Президента РФ от 7 мая 2018 г. № 204);

- Основные направления деятельности Правительства Российской Федерации на период до 2024 года;

- Национальный проект «Цифровая экономика»;

- Стратегия инновационного развития Российской Федерации;

- Стратегия научно-технологического развития Российской Федерации.

Кроме этого, отдельные элементы политики импортозамещения включены в отраслевые государственные программы:

- Государственная программа «Научно-технологическое развитие Российской Федерации 20192030 годы»;

- Государственная программа «Экономическое развитие и инновационная экономика 20132024 годы»;

- Государственная программа «Развитие промышленности и повышение ее конкурентоспособности 2013-2024 годы»;

- Государственная программа «Развитие авиационной промышленности 2013-2025 годы»;

- Государственная программа «Развитие судостроения и техники для освоения шельфовых месторождений 2013-2030 годы»;

- Государственная программа «Развитие фармацевтической и медицинской промышленности 2013-2024 годы»;

- Государственная программа «Развитие атомного энергопромышленного комплекса 2012-2027 годы»;

- Государственная программа «Информационное общество 2011-2024 годы»;

- Государственная программа «Развитие сельского хозяйства и регулирования рынков сельскохозяйственной продукции, сырья и продовольствия 2013-2025 годы».

Среди путей решения проблемы неопределенности при прогнозировании рынка продукции импортозамещения - разработка и принятие нормативного правового акта, определяющего долгосрочные приоритеты, сроки и ресурсы, выделяемые на осуществление политики импортозамещения.
Другая проблема прогнозирования рынка импортозамещения непосредственно связана с проблемами российских предприятий, участвующих в осуществлении стратегии импортозамещения. Среди таких проблем выделяются:

- отсутствие отечественных аналогов оборудования и сырья любого качества;

- низкое качество отечественного оборудования и сырья;

- недостаточная поддержка властями выпуска отечественного оборудования и сырья;

\ завышенные цены на отечественное оборудование и сырье;

- недостаточные объемы выпуска оборудования и сырья российскими предприятиями [6] и др.

Все эти проблемы создают ситуацию, при которой прогнозирование развития рынка импортозамещения может быть лишено смысла. Такое возможно в условиях сформировавшегося значительного спроса (как объекта прогнозирования) и недостаточного предложения, позволяющего удовлетворить данный спрос. Решение этой проблемы также требует системных решений, связанных с государственной поддержкой предприятий, участвующих в реализации политики импортозамещения; развития механизмов, стимулирующих предприятия к обновлению основных средств, поиску инновационных технологий удовлетворения спроса на продукцию, отнесенную к импортозамещающей.

Следующий блок проблем прогнозирования рынка импортозамещения связан с его крайней неоднородностью. Данный рынок представлен продукцией различных отраслей:

- выпуск оборудования для пищевой промышленности;

- тяжелое машиностроение;

- энергетическое машиностроение;

- электрохимическая и кабельная промышленность;

- нефтегазовое машиностроение;

- станкоинструментальная промышленность;

- судостроительное оборудование (в части судового комплектующего оборудования);

- радиоэлектронная промышленность;

- химическая и нефтехимическая промышленность;

фармацевтическая промышленность;

- медицинская промышленность;

промышленность обычных вооружений;

гражданское авиастроение;

двигателестроение;

- комплектующие и оборудование для транспортного машиностроения [7]. 
Каждая из приведенных отраслей в свою очередь может включать большое количество рыночных сегментов. Построение прогнозов требует учета особенностей объектов прогнозирования. В одних случаях это может быть приоритетное значение использования экспертных методов прогнозирования - в основном для отраслей с недостаточным объемом информации об их состоянии. В других случаях, в особенности, когда речь идет о массовом производстве, требуется приме- нение формализованных методов прогнозирования экономико-математических, методов экстраполяции и др.

Подводя итог, следует отметить существующую научную и практическую потребность решения выделенных выше проблем прогнозирования рынка импортозамещения. При этом следует учитывать наличие множества других частных проблем.

\section{ЛИТЕРАТУРА}

1. Артющик В.Д., Тихонов А.И. Применение методов прогнозирования спроса на авиационные двигатели в условиях импортозамещения на примере АО «0бъединенная двигателестроительная корпорация» // Московский экономический журнал. 2020. № 1. С. 58.

2. Изакова Н.Б. Состояние и перспективы рынка поливинилхлорида в России в меняющихся условиях деловой среды // Экономика, общество, человек: теория, методология, реальность: сборник научных публикаций: в 2-х частях. Министерство образования и науки Российской Федерации, Уральский государственный экономический университет. Екатеринбург, 2015. С. 170-176.

3. Иовлев Г.А. Импортозамещение на рынке сельскохозяйственной техники // Теория и практика мировой науки. 2017. № 9. С. 68-73.

4. Полякова И.С., Чибисова Е.Ю. Анализ рынка специальной техники и перспектив его развития в России // Экономика и предпринимательство. 2016. № 10-3 (75). C. 582-586.

5. Процессы импортозамещения на российском рынке продовольствия: состояние, тенденции, проблемы и прогнозы / Белова Т.Н., Конкина В.С., Куприянов В.В., Куприянова М.В.: Рязанский государственный агротехнологический университет имени П.А. Костычева. — Рязань: РГАТУ, 2019. — 188 с.

6. Ц Цухло С.В. Проблемы импортозависимости и импортозамещения в (для) российской промышленности. Институт экономической политики им. Е.Т. Гайдара (ИЭП). URL: https://www.iep.ru/ru/sergei-tcukhlo-problema-importozavisimosti-rossiiskoi-promyshlennosti-na-fone-stagnatcii-vnutrennego-rynka. html (дата обращения: 11.09.2021).

7. Чиновники определили приоритетные отрасли для импортозамещения. PБK. URL: https://www.rbc.ru/economics/20/01/2015/54be941b9a79473ac2a4 4d29 (дата обращения: 11.09.2021).

(c) Овчинников Алексей Павлович ( alexovchinnikov@mail.ru ).

Журнал «Современная наука: актуальные проблемы теории и практики»

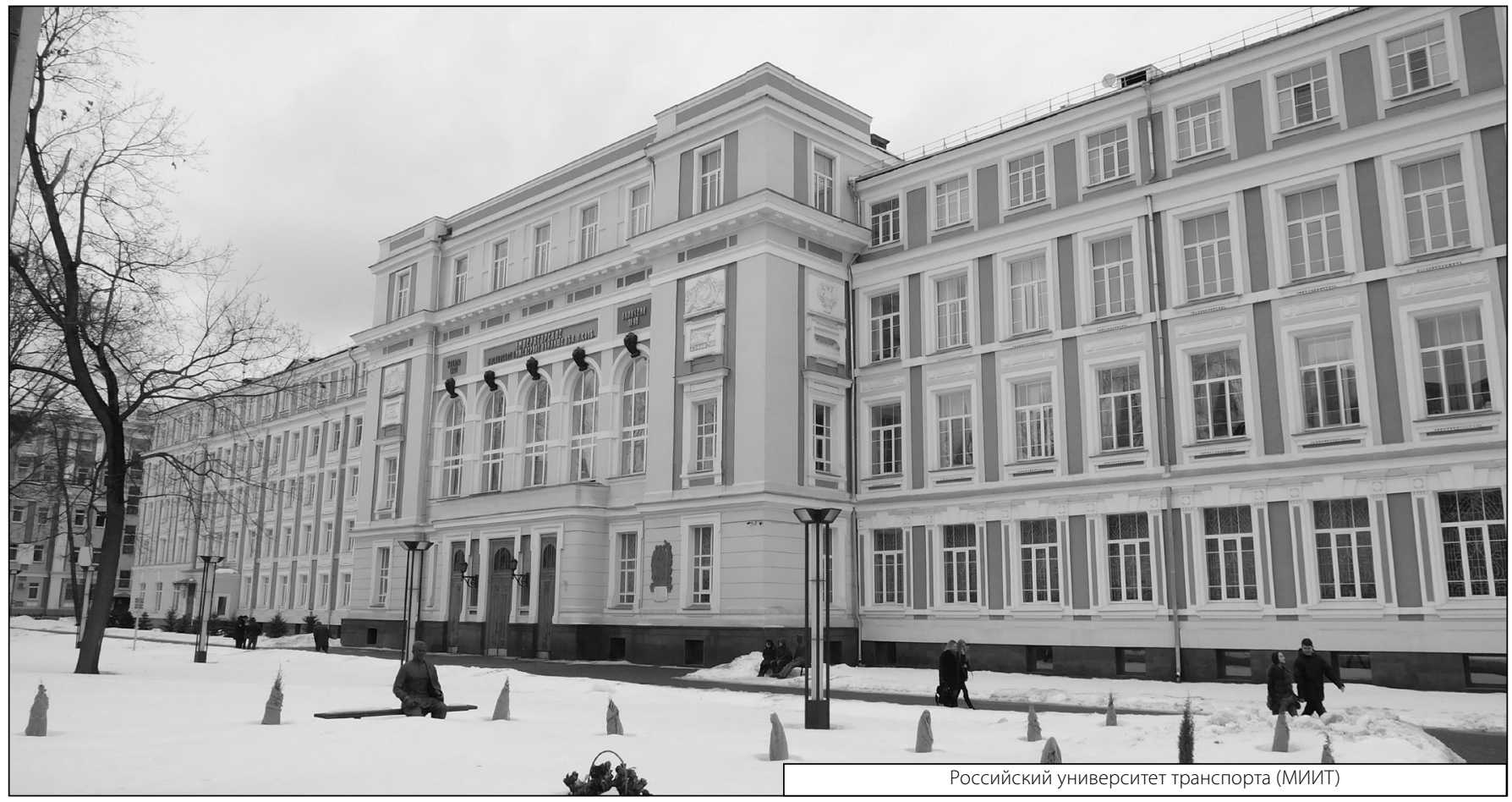

